
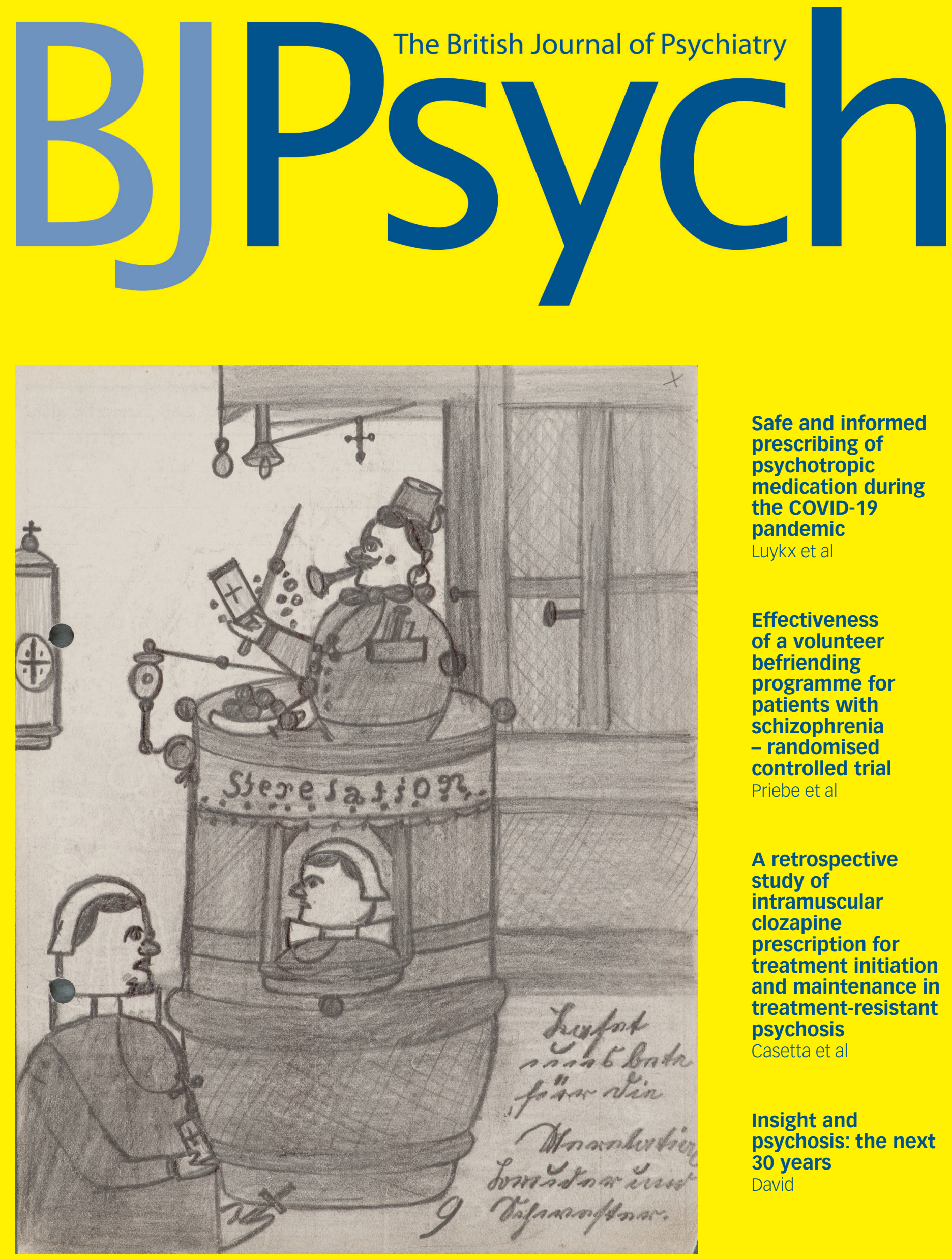

Safe and informed prescribing of psychotropic medication during the COVID-19 pandemic

Luykx et al

Effectiveness of a volunteer befriending programme for patients with schizophrenia - randomised controlled trial Priebe et al

\title{
A retrospective
} study of intramuscular clozapine prescription for treatment initiation and maintenance in treatment-resistant psychosis

Casetta et al

Insight and psychosis: the next 30 years

David 


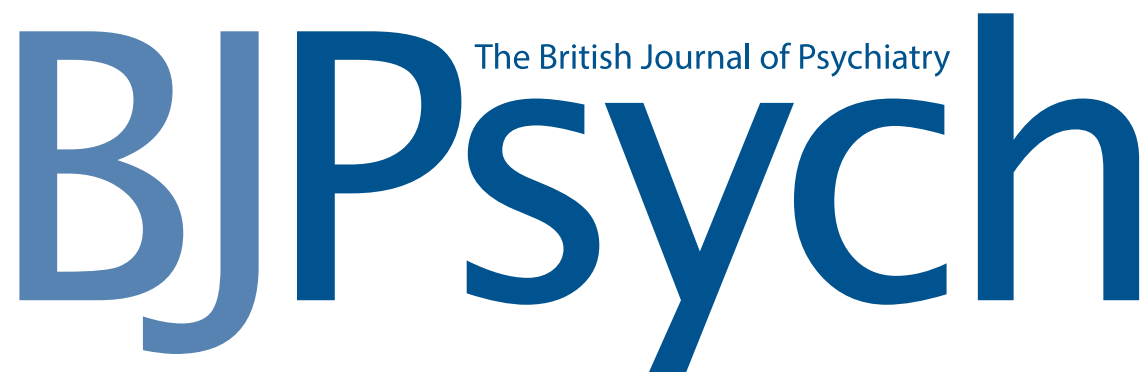

ISSN 0007 - 1250

Editor Kamaldeep Bhui CBE

\section{Deputy Editors}

Matthew Broome

William Lee

Gin Malhi

(Editorials Editor)

Giles Newton-Howes

(Reviews Editor)

Rachel Upthegrove

\section{Associate Editors}

Shehzad Ali

Mike Crawford

Elena Garralda

Joseph Hayes

Edgar Jones

Helen Killaspy

Anne Lingford-Hughes

Philip McGuire

Francis Anthony O’Neill

Jan Scott

James Shearer

Najma Siddiqi

Mustafa Soomro

\section{Editorial Advisors}

Sarah Byford

John Geddes

Martin Knapp

\section{International}

\section{Editorial Board}

Regi T. Alexander (UK)

Ricardo Araya (UK)

Allan Beveridge (UK)

(Book Reviews Editor)

Jonathan Bisson (UK)

Alec Buchanan (USA)
Colin Campbell (UK) (Correspondence Editor) (Debate Editor)

Mary Cannon (Ireland) Patricia Casey (Ireland) Andrew Cheng (Taiwan) Pamela Collins (USA) John Cookson (UK) Pim Cuijpers (The Netherlands) David Curtis (UK) Kimberlie Dean (Australia) Colin Drummond (UK) Simon Gilbody (UK) Peter Haddad (UK) Madelyn Hicks (USA) Philipp Homan (Switzerland) Louise Howard (UK) Khalida Ismail (UK) Navneet Kapur (UK) Kenneth Kaufman (USA) Steve Kisely (Australia) Stephen Lawrie (UK) Glyn Lewis (UK) Sean Lynch (UK) Kwame McKenzie (Canada) Marco Mula (UK) Roger Mulder (New Zealand) Aileen O'Brien (UK) (Debate Editor)

Martin Orrell (UK)

Femi Oyebode (UK)

(Book Reviews Editor) (Executive Contents Editor) Michael Phillips (China) Alexandra Pitman (UK) Rahul Rao (UK) (Highlights Editor) Zena Samaan (Canada)
Thomas Schulze (Germany) Bart Sheehan (UK) Sukhwinder Shergill (UK) Emily Simonoff (UK) Swaran Singh (UK) Athula Sumathipala (UK) Nori Takei (Japan) Derek Tracy (UK) Richard Williams (UK) Kiriakos Xenitidis (UK) (Correspondence Editor) Allan Young (UK)

\section{Trainee Editors}

Katherine Adlington Angharad de Cates Judith Harrison

\section{Statistical Advisors}

Eva Petkova

Pak Sham

Min Yang

\section{Staff}

Head of Publishing

Elizabeth Hay

Managing Editor

Alice Shuttleworth

Senior Publications

Coordinator

Dianndra Roberts

\section{Past Editors}

Eliot Slater 1961-72

Edward H. Hare 1973-77

John L. Crammer 1978-83 Hugh L. Freeman 1984-93 Greg Wilkinson 1994-2003 Peter Tyrer 2003-13

The British Journal of Psychiatry is published monthly by the Royal College of Psychiatrists (a charity registered in England and Wales (228636) and in Scotland (SC038369)). The Journal publishes original work in all fields of psychiatry. Manuscripts for publication should be submitted online at https://mc.manuscriptcentral.com/bjpsych.

All papers in this journal are peer-reviewed. No person is permitted to take any role in the peer-review of a paper in which they have an interest, defined as follows: fees or grants from, employment by, consultancy for, shared ownership in, or any close relationship with, an organisation whose interests, financial or otherwise, may be affected by the publication of the paper.

Subscriptions

British Journal of PSychiatry (ISSN 0007-1250) is published monthly. The six issues starting January 2020 comprise Volume 216 , the six issues starting July 2020 comprise Volume 217 . Orders from non-members of the College, which must be accompanied by payment, may be sent to any bookseller or subscription agent or direct to the publishers: Cambridge University Press, Journals Fulfilment Department, UPH, Shaftesbury Road, Cambridge CB2 8BS, UK, email journals@cambridge.org; or in the USA, Canada and Mexico, to Cambridge University Press, Journals Fulfilment Department, 1 Liberty Plaza, Floor 20, New York, NY 10006, USA, email subscriptions_newyork@cambridge.org. Japanese prices for institutions are available from Kinokuniya Company Ltd, P.O. Box 55, Chitose, Tokyo 156, Japan.

The annual subscription prices (including delivery by air but excluding VAT) for Volumes 216/217 are as follows:

\begin{tabular}{|lcc|}
\hline & INSTITUTIONS & INDIVIDUALS \\
\hline Print and online & $£ 567 / \$ 1011$ & $£ 457 / \$ 712$ \\
\hline Online only & $£ 465 / \$ 713$ & $£ 296 / \$ 463$ \\
\hline
\end{tabular}

Single issues are f54 (US\$97 in the USA, Canada and Mexico) plus postage. EU subscribers (outside the UK) who are not registered for VAT should add VAT at their country's rate. VAT registered subscribers should provide their VAT registration number. Claims for missing issues should be made immediately on receipt of the subsequent issue.

Queries from college members about missing or faulty copies should be sent to Customer Services, Cambridge University Press, email journals_societies@cambridge.org, tel. +44 (0)1223 326070.

\section{USPS ID Statement}

The British Journal of Psychiatry, ISSN 0007-1250, is published monthly by Cambridge University Press, UPH, Shaftesbury Road, Cambridge CB2 8BS, UK. The US annual subscription price is $\$ 976$ print and online/\$688 online only for institutions and $\$ 687$ print and online/\$447 online only for individuals. Airfreight and mailing in the USA by agent named WN Shipping USA, 156-15, 146th Avenue, 2nd Floor, Jamaica, NY 11434, USA. Periodicals postage paid at Brooklyn, NY 11256. US Postmaster: Send address changes to The British Journal of Psychiatry, WN Shipping USA, 156-15, 146th Avenue, 2nd Floor, Jamaica, NY 11434, USA. Subscription records are maintained at Cambridge University Press, UPH, Shaftesbury Road, Cambridge CB2 8BS, UK. Air Business Ltd is acting as our mailing agent.

\section{Online access}

British Journal of Psychiatry is hosted on the Cambridge Core service at https://www.cambridge.org/core/journals/the-british-journal-ofpsychiatry.

Information about the college's publications is available at https://mmw. rcpsych.ac.uk

Instructions to authors

Full instructions to authors are given at https://www.cambridge.org/core/ journals/the-british-journal-of-psychiatry/information/instructionscontributors.

\section{Advertising}

Correspondence and copy should be addressed to:

Stephen H. P. Mell, Advertising Manager, PTM Publishers Ltd, 41 Hart Close, Uckfield, East Sussex TN22 2DA, UK (email advertising@ptmpublishers. com; tel. 02086420162

Founded by J. C. Bucknill in 1853 as the Asylum Journal and known as the Journal of Mental Science from 1858 to 1963.

(The Royal College of Psychiatrists 2020. Unless so stated, material in the British Journal of Psychiatry does not necessarily reflect the views of the Editor or the Royal College of Psychiatrists. The publishers are not responsible for any error of omission or fact.

Printed in Great Britain by Henry Ling Limited, The Dorset Press, 23 High East Street, Dorchester, Dorset DT1 1HD.

This journal issue has been printed on FSCTM-certified paper and cover board. ESC is an independent, non-governmental, not-for-profit organization established to promote the responsible management of the world's forests. Please see wnw.fsc.org for information.

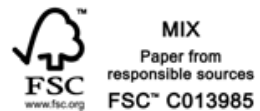




\section{BJPsych}

\section{Contents}

A33 Editorial Board

A35 Highlights of this issue

\section{Editorials}

467 What kind of in-patient psychiatry for Africa? Report from Zimbabwe

Derek Summerfield

469 Questioning the status of aberrant speech patterns as psychiatric symptoms

Eric J. Tan and Susan L. Rossell

471 Safe and informed prescribing of psychotropic medication during the COVID-19 pandemic

Jurjen J. Luykx, Sisco M.P. van Veen, Arne Risselada, Paul Naarding, Joeri K. Tijdink and Christiaan $\mathrm{H}$. Vinkers

474 psychiatry in theatre - Under my grandmother's scarf: the healing effects of performance art

Caroline Giroux

475 Three challenges that the COVID-19 pandemic represents for psychiatry

Ladislav Kesner and Jiř́ Horáček

\section{Papers}

477 Effectiveness of a volunteer befriending programme for patients with schizophrenia: randomised controlled trial

Stefan Priebe, Agnes Chevalier, Thomas Hamborg, Eoin Golden, Michael King and Nancy Pistrang

484 Early intervention in psychosis: health economic evaluation using the net benefit approach in a real-world setting Caragh Behan, Brendan Kennelly, Eric Roche, Laoise Renwick, Sarah Masterson, John Lyne, Brian O’Donoghue,

John Waddington, Catherine McDonough, Paul McCrone and Mary Clarke

491 Ten-year employment patterns of patients with first-episode schizophrenia-spectrum disorders: comparison of early intervention and standard care services

Sherry Kit Wa Chan, Herbert H. Pang, Kang K. Yan, Christy Lai Ming Hui, Yi Nam Suen, Wing Chung Chang, Edwin Ho Ming Lee, Pak Sham and Eric Yu Hai Chen

498 In the aftermath of clozapine discontinuation: comparative effectiveness and safety of antipsychotics in patients with schizophrenia who discontinue clozapine Jurjen J. Luykx, Noraly Stam, Antti Tanskanen, Jari Tiihonen and Heidi Taipale

506 A retrospective study of intramuscular clozapine prescription for treatment initiation and maintenance in treatmentresistant psychosis

Cecilia Casetta, Ebenezer Oloyede, Eromona Whiskey, David Michael Taylor, Fiona Gaughran, Sukhi S. Shergill, Juliana Onwumere, Aviv Segev, Olubanke Dzahini, Sophie E. Legge and James Hunter MacCabe
514 Comparison of clinical outcomes following 2 years of treatment of first-episode psychosis in urban early intervention services in Canada and India

Ashok Malla, Srividya N. Iyer, Thara Rangaswamy,

Padmavati Ramachandran, Greeshma Mohan, Aarati Taksal,

Howard C. Margolese, Norbert Schmitz and Ridha Joober

\section{Analysis}

521 Insight and psychosis: the next 30 years Anthony S. David

524 psychiatry in philosophy - David Hume and the 'Disease of the Learned' Matthew Butler

\section{Columns}

$\begin{array}{ll}525 & \text { Corrigendum } \\ 526 & \text { Ten books } \\ 529 & \text { Book reviews } \\ 531 & \text { Contents of the American Journal of Psychiatry } \\ 531 & \text { Contents of BJPsych Advances }\end{array}$

532 Kaleidoscope

534 psychiatry in pictures - The West Riding of Yorkshire pauper Lunatic Asylum at Wakefield, 1814-1995 R.H.S. Mindham

\section{Cover picture}

(c) Prinzhorn Collection, University Hospital Heidelberg Sterelation/9 by Wilhelm Werner, Inventory Number 8083(2008)fol.9.

This picture is one of 44 pencil drawings by Wilhelm Werner, a psychiatric patient who was murdered by the Nazis. It is believed to be the only preserved work of visual art by the 400,000 people whom the Nazis forced to undergo sterilisation. Werner's drawings have recently been acquired by the Prinzhorn

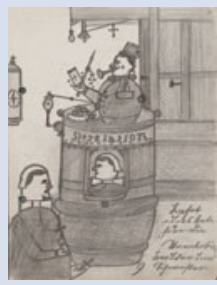
Collection at Heidelberg University Hospital in southern Germany, which is known for one of the largest collections of art by psychiatric patients in the world. Its Director is the art historian, Thomas Röske.

Born a Catholic on the 18th September 1898, Werner was diagnosed with 'idiocy', though this is disputed by Röske, who argues that Werner could read and write. In October 1940, when he was 42, Werner was transported to Pirna Sonnenstein asylum, near Dresden. He was subsequently murdered in its gas chambers as part of the Nazis' 'euthansia' extermination programme. Werner's drawings depict scenes from the sterilisation clinic. This drawing shows a contraption labelled 'Sterelation', which was his term for sterilisation. Inside sits a nurse with a white hat, whilst on top there is a clown-like figure, who clutches a sharp implement and a book displaying a cross, while his other hand holds a testicle next to a plate containing more testicles. Outside, a second nurse holds a cross and a holy book. Werner depicts sterilisation as a literal castration, though as Röske points out, the Law for the Prevention of Genetically Diseased Offspring only stated that patients should be rendered infertile.

We are always looking for interesting and visually appealing images for the cover of the Journal and would welcome suggestions or pictures, which should be sent to Dr Allan Beveridge, British Journal of Psychiatry, 21 Prescot Street, London, E1 8BB, UK or bjp@rcpsych.ac.uk. 